\title{
An 8/6 SRM Drive with a Multilevel Topology Based on a Cross-Switched Configuration
}

\author{
V. Fernão Pires \\ Department of Electrical Engineering \\ Sustain.RD, ESTSetúbal, Instituto \\ Politécnico Setúbal \\ INESC-ID Lisboa \\ Setúbal, Portugal \\ vitor.pires@estsetubal.ips.pt \\ Armando Cordeiro \\ ADEEA \\ ISEL, Instituto Politécnico de Lisboa \\ INESC-ID Lisboa \\ Lisboa, Portugal \\ acordeiro@deea.isel.ipl.pt
}

\author{
Daniel Foito \\ Department of Electrical Engineering \\ Sustain.RD, ESTSetúbal, Instituto \\ Politécnico Setúbal \\ CTS/UNINOVA \\ Setúbal, Portugal \\ acordeiro@deea.isel.ipl.pt
}

\author{
A. J. Pires \\ Department of Electrical Engineering \\ Sustain.RD, ESTSetúbal, Instituto \\ Politécnico Setúbal \\ CTS/UNINOVA \\ Setúbal, Portugal \\ armando.pires@estsetubal.ips.pt \\ J. F. Martins \\ Department of Electrical Engineering \\ FCT/UNL \\ CTS/UNINOVA \\ Caparica, Portugal \\ jf.martins@fct.unl.pt
}

\begin{abstract}
SRM drives based on multilevel power electronic converter presents several advantages, like reducing the switching frequency and improve the operation of the motor under high speed. In this way, several multilevel power converter topologies have been developed for the $S R M$ drives. In line with this, this paper proposes a new multilevel power converter topology for the 8/6 SRM drive. The topology was developed with the purpose to reduce the number of power semiconductors, without reducing the performance of the motor. The proposed topology was designed in a way that uses crossover switches. The operation of the power converter topology in all of their modes is analyzed in a detailed way. The verification of the global system performance (drive and motor) is realized by the implementation of simulation studies. Indeed, through these studies it is verified that at low speed operation the switching frequency is reduced, but maintaining the application of the maximum voltage during the magnetization and demagnetization process.
\end{abstract}

Keywords - switched reluctance motor (SRM), reduced power semiconductors, multilevel converter, T-Type

\section{INTRODUCTION}

One of the very well-known motors that were not massively adopted is the switched reluctance motor (SRM). Indeed, this motor is known for many years, more specifically since the $19^{\text {th }}$ century. An important problem associated to the use of this motor was the impossibility to connect it directly to a $D C$ or $A C$ power source. However, with the development of the power electronics area, this problem practically disappeared making their use become now a reality [1]. Thus, since now the connection of this motor to the power supply is very easy through the power converter, it becomes more interesting due to its simplicity and structural strength. In fact, this motor is now considered to be use in several applications, such as, electric traction, wind generators, water pumping systems and air conditioning fans or even in applications with required position control [2-6].
One of the key aspects related to the SRM is its association with a power electronic converter. Thus, several power converter topologies have been proposed and used in several applications. The majority of the topologies are based on the power converters that generate three-voltage levels. The main topology have been the asymmetric bridge converter $[7,8]$. However, other three-voltage level topologies have been proposed, namely being many of them developed with the purpose to reduce the number of power semiconductors, or to increase the reliability. Under the consideration of the reduction of the power semiconductors several topologies have been presented. One of the approaches to reduce that number is with the elimination of one leg per phase using two capacitors serial connected to obtain a neutral point [9-11]. Another approach is through the shared phase winding converter, in which in one of the sides two or more winding phases share the same power semiconductor(s) $[12,13]$. Regarding the point of view of the reliability, the topologies are designed in an opposite way. The system normally requires extra power semiconductors, and sometimes even static or mechanical relays [14-16]. In order to provide voltage regulation capability to the $S R M$ drive, the association of the quasi-Z converter was also proposed $[17,18]$.

Another aspect related with the choice of the power electronic converters to be used in the $S R M$ drive, is to adopt topologies that allows to generate more than three-levels (multilevel). Indeed, in the last years topologies with this characteristic have been adopted due to their advantages associated to the improvement of the SRM performance, especially at high speeds, as well as, the reduction of the power semiconductors switching frequency. In this way, several multilevel topologies have been tested and proposed. The first approaches were based on the classical inverter multilevel topologies, namely, the cascaded H-bridge, flying capacitor and neutral point clamped [19-22]. Then topologies based on the modular multilevel converter $(M M C)$ and T-Type were proposed [21-25]. Another different approach was used through 
a quasi-Z converter in which was derived two poles with different voltage levels [26].

Under the point of view of exploring new power electronic converters that can be applied to the SRM drive, this paper proposes a new multilevel topology. Besides the purpose of the improvement of the $S R M$ high-speed operation and to reduce the power semiconductors switching frequency, it also has the objective to reduce the number of components. Due to the developed topology type, the converter is considered as based on a cross-switched configuration. In reality, the topology was designed in a way that uses crossover switches. The proposed $S R M$ drive will be studied as well as verified its performance, by simulation tests.

\section{IMPACT OF THE POWER CONVERTER IN THE SRM WINDINGS CURRENT RIPPLE}

The $S R M$ operation principle is based on the variation of the magnetic reluctance with the rotor position. Each stator phase has to be energized and deenergized at proper times and the mathematical model is usually considered complex due to the nonlinearity of its magnetic circuit. Neglecting the mutual inductance, the $S R M$ electrical equation for each phase is done by (1):

$$
u_{j}=R_{j} i_{j}+\frac{\partial \psi_{j}\left(\theta_{r}, i_{j}\right)}{\partial i_{j}} \frac{d i_{j}}{d t}+\frac{\partial \psi_{j}\left(\theta_{r}, i_{j}\right)}{\partial \theta_{r}} \omega_{r}
$$

where $u_{j}$ is the $j$ phase voltage, $i_{j}$ the phase current, $R_{j}$ the phase resistance, $\theta_{r}$ the rotor position, $\omega$. the rotor speed and $\psi_{j}\left(\theta_{r}, i_{j}\right)$ the phase linkage flux. The last term in equation (1) corresponds to the back $E M F$, which depends on the rotor speed, $\omega_{r}$.

The linkage flux of each phase $\psi_{j}\left(\theta_{r}, i_{j}\right)$ can be expressed by (2):

$$
\psi_{j}\left(\theta_{r}, i_{j}\right)=L_{j}\left(\theta_{r}\right) i_{j}
$$

where the magnetic self-inductance coefficient, $L_{j}$, is introduced and it is considered, in this analysis, not dependent on the phase current, $i_{j}$.

Taking into acount eq. (2) in (1) and considering a short time period in the magnetizing process of the $j$ phase (motor functioning, as an example), it is possible to assume some simplifications in order to highlight major conclusions, with no loss of generality. In this way, equation (1) can be rewritten as (3).

$$
\Delta t=\frac{1}{L_{j}}\left(\frac{\Delta i_{j}}{U_{j}-R_{j} I_{j}-k I_{j} \omega_{r}}\right)
$$

where the time derivative of the phase current was transformed in a finite variation and the phase input voltage, that assumes different discrete values (positive, negative or null values) is assumed to be constant $\left(U_{j}\right)$, the phase current is also assumed to have an average value $\left(I_{j}\right)$, and the magnetic self-inductance coefficient $\left(L_{j}\right)$ is assumed to have a linear dependence on the rotor position, which in eq. (3) is expressed by a constant, $k$.

Based on eq. (3) it can be concluded that the switching frequency can be diminished, keeping a constant ripple for the current, having lower input voltage values, particularly for low speed values. Of course that the voltage signals can change and the influence of speed can be "in favour" or "against" the input voltage, but the voltage average value is greatly influenced by the speed level. Nevertheless, maintaining a constant current ripple, the frequency is greatly influenced by the voltage levels, increasing its value if the voltage absolute values are high or decreasing if low voltage levels are used. So, with a multilevel converter it is possible to better adapt the operation frequency, keeping the current ripple in appropriate levels. Another aspect in favour of the use of multilevel converters is during the phase commutation periods, particularly for high speed operation, where the back $E M F$ of the motor will present high values and the input voltage should be even higher in order to minimize the commutation time and also to assure the current level.

\section{SRM DRIVE With A MultileVEl CONVERTER BASED ON A CROSS-SWITCHED CONFIGURATION}

As said in the first section, the classical topology of the power converter used for the SRM drive is the asymmetric bridge converter that only allows to generate three voltage levels $\left(-V_{D C}, 0\right.$ and $\left.+V_{D C}\right)$. As presented in Fig. 1 (drive for the 8/6 SRM) this topology consists of legs with a transistor and a diode. Due to the limitation of the voltage levels the performance of the drive is limited and generates high switching frequency at low speeds.

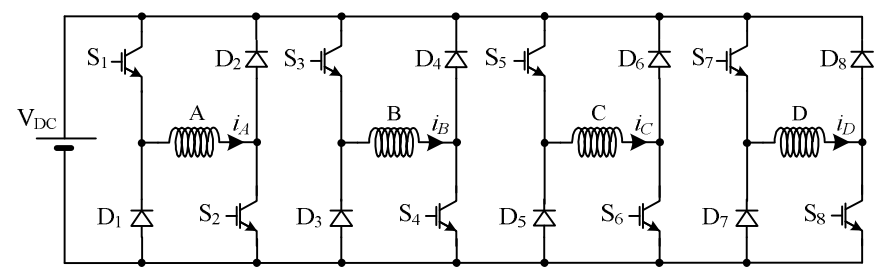

Fig. 1. Topology of the asymmetric bridge converter used in SRM drives.

With the purpose of overcoming the limitations associated to the three-level converters, several multilevel topologies have been proposed. Indeed, these topologies allow to ensure a fast magnetization and demagnetization of the motor windings through the application of the maximum voltage levels (positive and negative). On the other hand, allows to apply reduced voltage levels at low speeds, by which will reduce the switching frequency. The problem associated to this type of topologies is that increases the number of power semiconductors. This problem will affect the cost, size, weight and efficiency of the drive. In this context, it is proposed a new multilevel topology for the $S R M$ drive, in which one of the design criteria is to avoid a high number of power semiconductors. In Fig. 2 this new topology for the $S R M$ drive is presented. Analyzing this figure is possible to verify that the circuit uses a principle similar to the cascaded H-bridge topology [19]. However, it requires a less number of $D C$ power sources and power semiconductors. In fact, it only requires three $D C$ sources and 8 legs with a transistor and a diode, which is the same number of the conventional (asymmetric bridge converter). However, besides the legs, the topology requires two extra transistors and two extra diodes. Nevertheless, this is a reduced number of extra power semiconductors to obtain a multilevel topology. It is also 
possible to verify that the topology uses the extra components to obtain crossover switches. In this way, this proposed topology can be considered as a multilevel topology based on a crossswitched configuration. Regarding the machine windings, on one of the sides all windings will be connected to each leg of the module with four legs. For the other side, two of the legs will be connected to the module of two legs, while the other two will be connected to the other modules with two legs. In order to avoid interferences during the magnetization and demagnetization process, the windings that will be connected to the same module with two legs will not be the adjacent, by which it is used the windings $\mathrm{AC}$ and windings $\mathrm{BD}$.

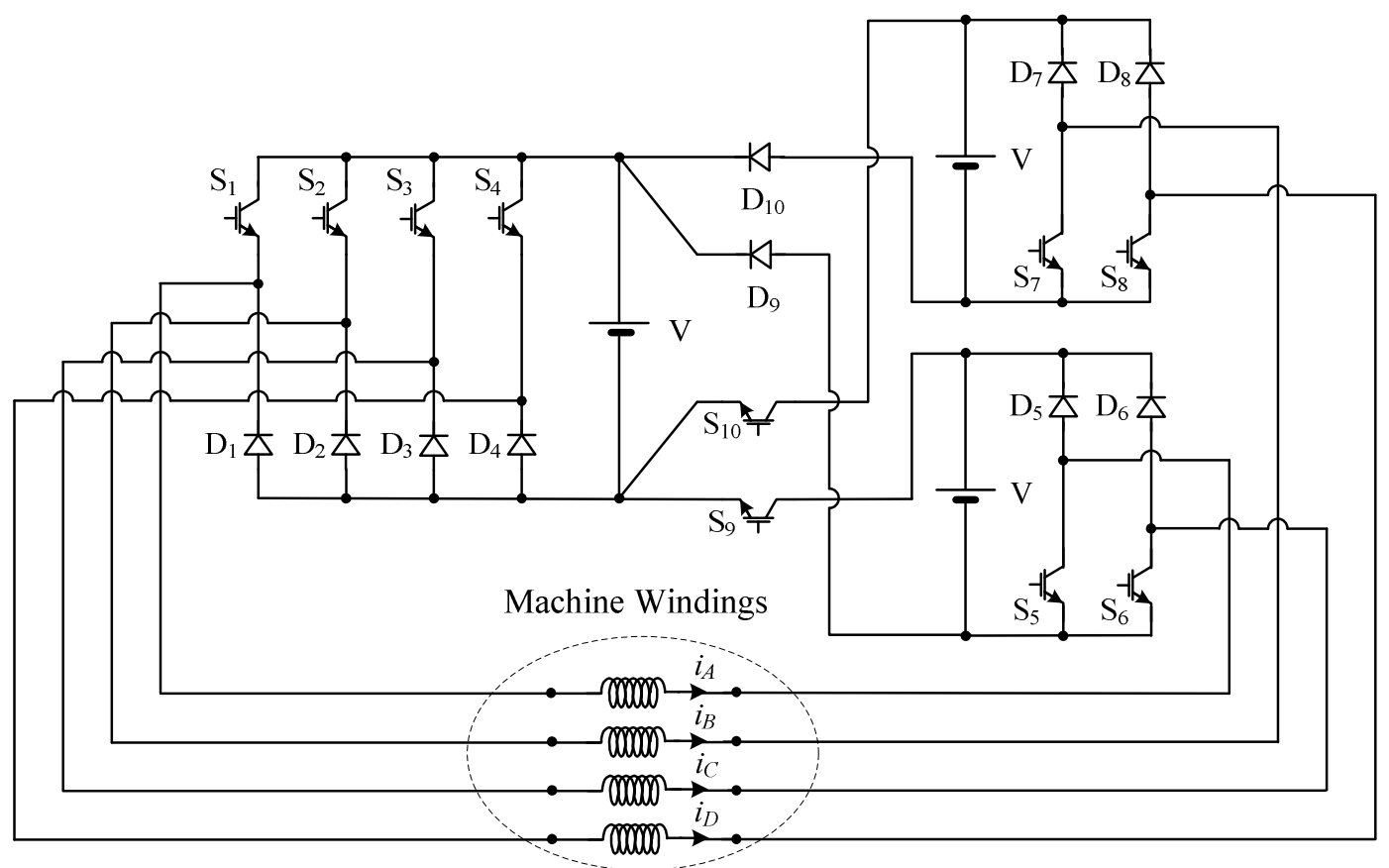

Fig. 2. Proposed multilevel topology based on a cross-switched configuration.

The analysis of the proposed drive can be realized by the several operation modes associated to the converter. So, this analysis will be made for one of the phases, since for the other ones is the same. The operation modes are function of the switching states. In accordance with this, there are five operation modes. Using phase A for this analysis, each of the modes is described:

First Mode: in this mode, switches $S_{1}, S_{5}$ and $S_{9}$ are $O N$ resulting in the circuit of Fig. 3 a). All the diodes are $O F F\left(D_{l}\right.$, $D_{2}$ and $D_{9}$ ). From the analysis of the resulted circuit is possible to verify that in this mode it is applied the maximum positive voltage $\left(+2 V_{D C}\right)$. Due to this, this mode will allow for a fast magnetization.

Second Mode: this mode is associated to the switches $S_{l}$ and $S_{9}$ and diode $D_{2}$ in $O N$ state. Switch $\mathrm{S}_{5}$ and diodes $D_{l}$ and $D_{9}$ are in $O F F$ state. This will allow to apply the intermediate positive voltage, namely $+V_{D C}$. In this way, this mode can be used to increase/decrease the winding current in a moderate way, allowing in this way to reduce the switching frequency.

Third Mode: in this mode only switch $S_{9}$ is in $O N$ state, but the diodes $D_{1}$ and $D_{2}$ are also in $O N$ state. On the other hand, switches $S_{1}, S_{2}$ and diode $D_{9}$ are in $O F F$ state. This results in the application of a zero voltage to the $S R M$ winding. In this way, due to the resistance associated to the motor winding $S R M$, there will be a very slowly demagnetization.
Fourth Mode: this mode is associated to the single switch in $O N$ state $S_{1}$, as well as diodes $D_{5}$ and $D_{9}$ in $O N$ state. Regarding switches $S_{5}, S_{9}$ and diode $D_{l}$, they are in $O F F$ state. In this mode, the intermediate negative voltage, $-\mathrm{V}_{\mathrm{DC}}$, will be applied to the motor winding. Thus, the demagnetization of the winding will be realized in a moderate way.

Fifth Mode: in this mode all the switches $\left(S_{1}, S_{5}\right.$ and $\left.S_{9}\right)$ are in $O F F$ state. On the other hand, all the diodes $\left(D_{1}, D_{5}\right.$ and $\left.D_{9}\right)$ will be in $O N$ state. From the analysis of the resulting circuit is possible to verify that in this case the maximum negative voltage $\left(-2 V_{D C}\right)$ will be applied to the motor winding. In this way, through this mode, it is possible to obtain a fast demagnetization.

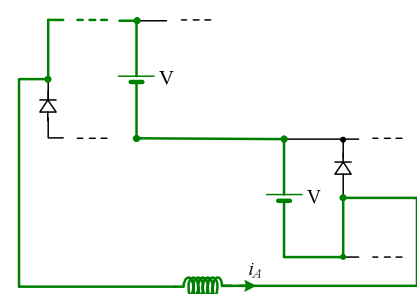

a) Mode 1: $+\mathbf{2 V}$

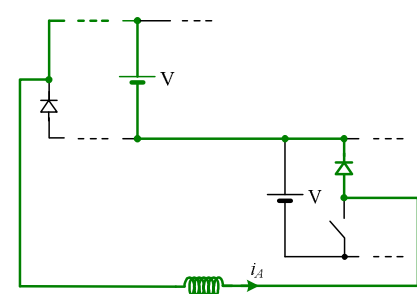

b) Mode 2: $+\mathbf{V}$ 


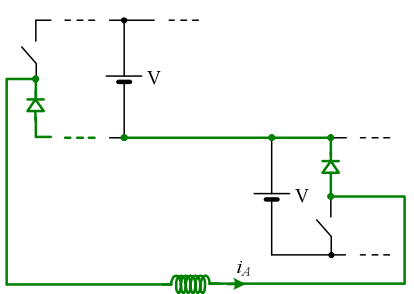

c) Mode 3: $\mathbf{0 V}$

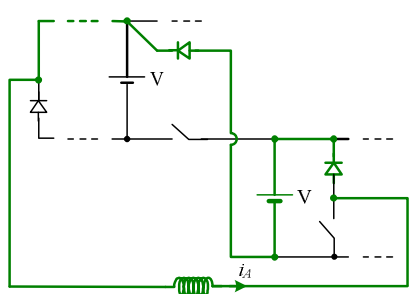

d) Mode 4: - V

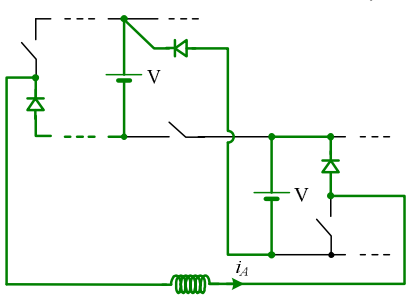

e) Mode 5: $\mathbf{- 2 V}$

Fig. 3. Operating modes of the proposed multilevel converter for phase A.

For the proposed power converter there will be a current controller (as usually in this kind of motors) for the motor winding currents. It will be adopted the hysteresis current controller. The input of the hysteresis block will be the difference between the reference and the measured winding currents. However, the strategy must be different at the output since in this case there are five operation modes. In order to adapt to this converter, it is proposed a five-level hysteresis. So, in accordance with the input signal, at the output of the hysteresis it will be generated a signal that can take five levels $(-2,-1,0,1,2)$. The gating signals will be function of this signal. The generation of the gating signals will be implemented by a look-up table. Considering phase A as an example, Table I shows the combination that the look-up table must take into consideration to generate the gating signals. The final block diagram of the control system is shown in Fig. 4.

TABLE I. COMBINATION OF THE LOOK UP TABLE FOR PHASE A

\begin{tabular}{|c|c|c|}
\hline $\begin{array}{c}\text { Output of the } \\
\text { hysteresis }\end{array}$ & $\begin{array}{c}\text { Operation } \\
\text { mode }\end{array}$ & $\begin{array}{c}\text { Switches and diodes in } \\
O N \text { state }\end{array}$ \\
\hline+2 & First & $S_{1}, S_{5}$ and $S_{9}$ \\
\hline+1 & Second & $S_{1}, S_{9}$ and $D_{5}$ \\
\hline 0 & Third & $S_{9}, D_{1}$ and $D_{5}$ \\
\hline-1 & Fourth & $S_{5}, D_{1}$ and $D_{9}$ \\
\hline-2 & Fifth & $D_{1}, D_{5}$ and $D_{9}$ \\
\hline
\end{tabular}

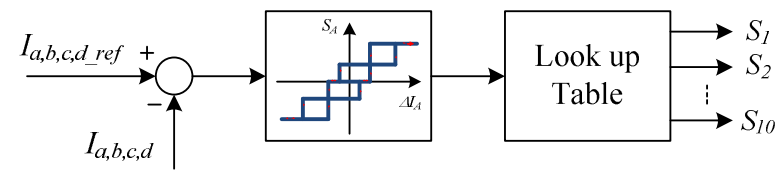

Fig. 4. Control system of the converter.

\section{NUMERICAL VERIFICATION}

The behavior of the proposed $S R M$ drive was verified through numerical simulations. The realization of these simulations was made through the very well-known program Matlab/Simulink. It was used a model of the 8/6 SRM machine that exists in the libraries of that program. For the three $D C$ sources it was adopted a value of $120 \mathrm{~V}$. It was also used an $8 \mathrm{Nm}$ load applied to the motor. Regarding the turn-on and turn-off angles, it was used predefined and fixed values in any operation point of $37,5^{\circ}$ and $52,5^{\circ}$ respectively.

With the purpose to test the proposed $S R M$ drive, several tests for different speeds were made. The first test was realized at low speed, $300 \mathrm{rpm}$. The obtained results for the $S R M$ winding currents and voltage applied to winding phase $A$ are presented in Figs. 5 and 6 . From Fig. 5 it is possible to verify that the winding currents follow the reference $(6 \mathrm{~A})$, presenting the typical waveforms. Since the speed is low the current is in accordance with the defined reference, by which presents a ripple associated to the switching frequency of the switches. This can also be confirmed by the result of the voltage applied to winding phase $A$, in which between the turn-on and turn-off angles of this phase the voltage changes between $+V_{D C}$ and zero. The exception is during the transition in the turn-on angle in which the applied voltage is the maximum to quickly magnetize the winding. This also shows the multilevel operation of the proposed power converter. Since the applied voltage to maintain the current at the reference voltage is between $+V_{D C}$ and zero, the switching frequency will be reduced, compared with the application of the maximum voltage. It should be noted that in this operation mode the intermediate voltage $+V_{D C}$ is higher than the back $E M F$ (and far away from this voltage when compared with the maximum allowed voltage $+2 V_{D C}$ ) by which when this voltage level is applied the winding current will increase.

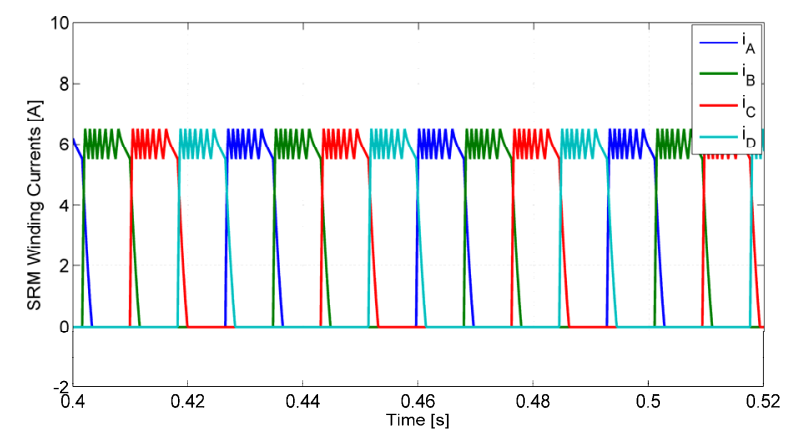

Fig. 5. Current in one SRM phase for a reference speed of $300 \mathrm{rpm}$. 


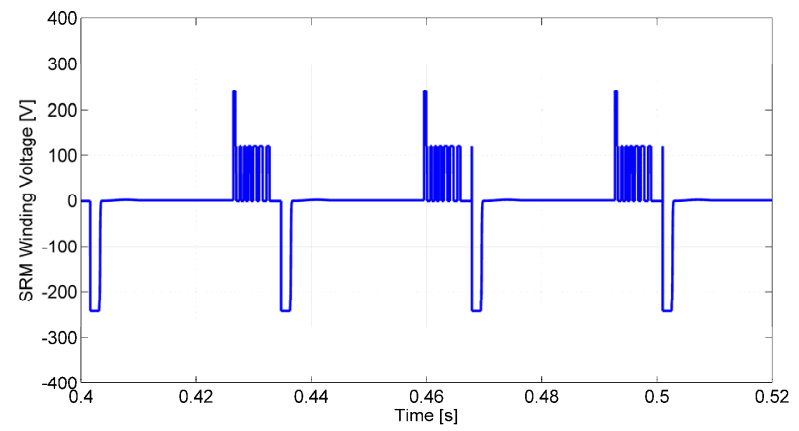

Fig. 6. Voltage applied to the SRM winding phase A for a reference speed of $300 \mathrm{rpm}$.

A second test, with a higher speed, $900 \mathrm{rpm}$, to verify the behavior of the converter, was also realized. In this test a current reference of $6 \mathrm{~A}$ is maintained. Figs. 7 and 8 show the obtained results for the $S R M$ winding currents and voltage applied to winding phase A. These figures show that the converter still maintain their multilevel operation. However, instead of a continuous change between $+V_{D C}$ and zero between the turn-on and turn-off angles of phase A under analysis, now the change is between $+2 V_{D C}$ and $+V_{D C}$. In this operation mode the intermediate voltage is lower than the back $E M F$, by which it can be used to decrease the winding current instead of using the zero voltage reducing in this way the switching frequency.

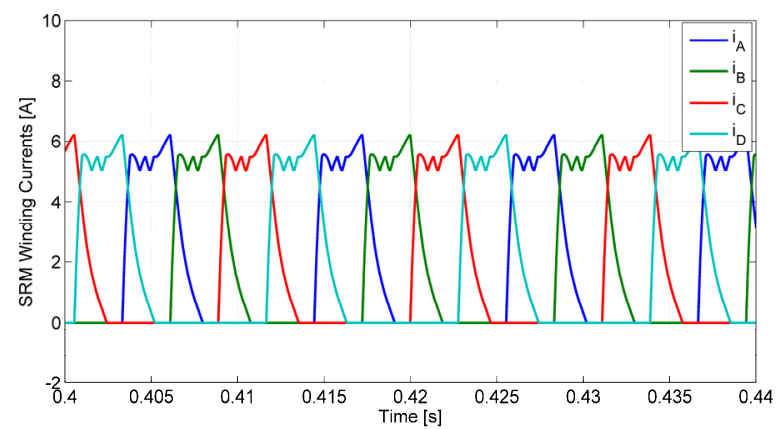

Fig. 7. Current in one SRM phase for a reference speed of $900 \mathrm{rpm}$.

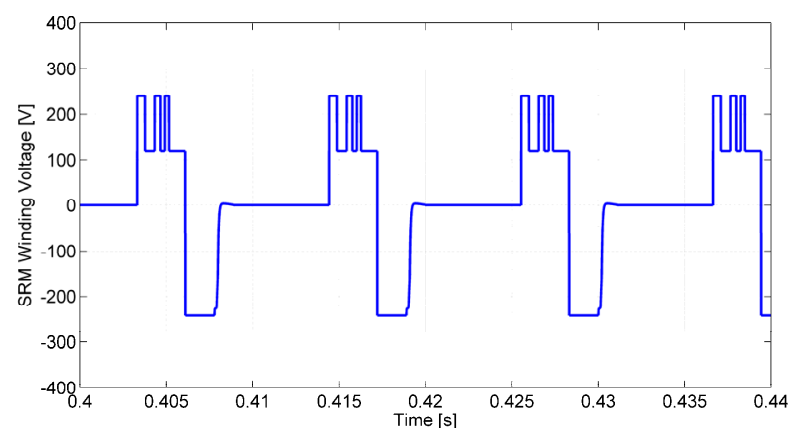

Fig. 8. Voltage applied to the SRM winding phase A for a reference speed of $900 \mathrm{rpm}$.

A final test, realized at high speed, was also made. In this case, it was adopted a speed of $1250 \mathrm{rpm}$. The obtained results for the $S R M$ winding currents and voltage applied to winding phase $\mathrm{A}$ are presented in Figs. 9 and 10. In this case it is possible to verify that the converter lost their multilevel operation. This is expected since the drive is operating at their limit. In fact, it is possible to verify by Fig. 10 that the voltage applied to phase A between the turn-on and turn-off angles is always at the maximum available $\left(+2 V_{D C}\right)$.

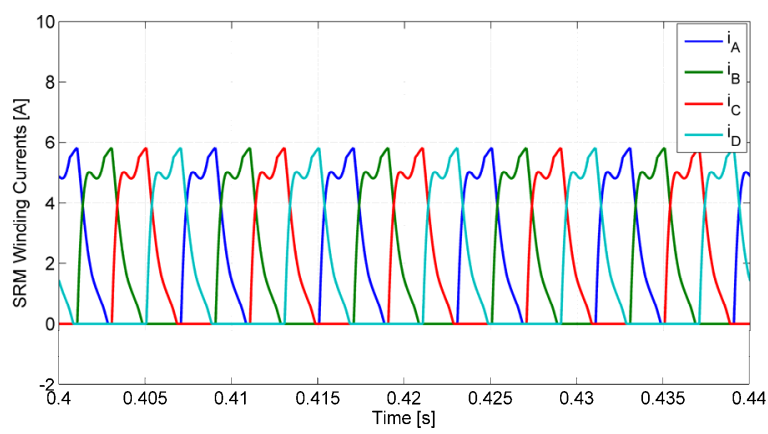

Fig. 9. Current in one SRM phase for a reference speed of $1250 \mathrm{rpm}$.

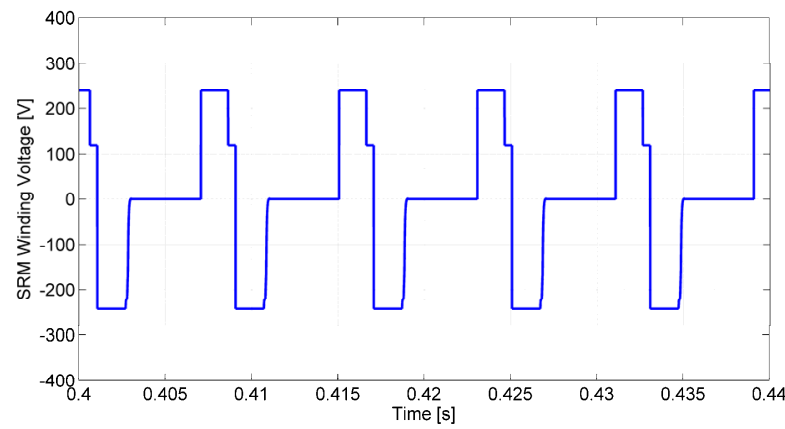

Fig. 10. Voltage applied to the SRM winding phase A for a reference speed of $1250 \mathrm{rpm}$.

\section{CONCLUSIONS}

A new multilevel power converter developed for an 8/6 SRM drive was presented in this paper. This developed topology was designed to maintain the performance of the motor but with a reduction of the number of power semiconductors. Due to the use of crossover switches it can be considered that the circuit resulted in a cross-switched configuration. To verify the functioning of the proposed converter, the topology was analyzed in a detailed way, namely through the description of the several possible operation modes. From this description it was possible to verify that five voltage levels can be applied to the $S R M$ windings. A control system that was used with this circuit was also presented. Finally, the behavior of the proposed $S R M$ drive was verified through several numerical simulations. These simulations were realized for different speeds in order to confirm the characteristics of the drive.

\section{ACKNOWLEDGMENT}

The work reported in this article was supported by national funds through FCT under contract UID/CEC/50021/2019 and UID/EEA/00066/2019. 


\section{REFERENCES}

[1] M. Barnes, C. Pollock, "Power electronic converters for switched reluctance drives", IEEE Trans. on Power Electron., vol.13, no.6, pp.1100-1111, Nov 1998.

[2] E. Bostanci, M. Moallem, A. Parsapour, B. Fahimi, "Opportunities and Challenges of Switched Reluctance Motor Drives for Electric Propulsion: A Comparative Study," IEEE Trans. Transportation Electrification, vol. 3, no. 1, pp. 58-75, March 2017.

[3] Z. Yang, F. Shang, I. P. Brown, M. Krishnamurthy, "Comparative Study of Interior Permanent Magnet, Induction, and Switched Reluctance Motor Drives for EV and HEV Applications," IEEE Trans. Transportation Electrification, vol. 1, no. 3, pp. 245-254, October 2015.

[4] S. Li, S. Zhang, T. G. Habetler, R. G. Harley, "Modeling, Design Optimization, and Applications of Switched Reluctance Machines-A Review," IEEE Trans. Industry Applications, vol. 55, no. 3, pp. 26602681, May-June 2019.

[5] P. Lobato, J. A. Dente, J. F. Martins, A. J. Pires, "Scale Models Formulation of Switched Reluctance Generators for Low Speed Energy Converters", IET Electric Power Applications, vol. 9, Issue 9, pp. 652659, Nov. 2015.

[6] Silviano Rafael, P.J. Costa Branco, A. J. Pires, "Sliding mode angular position control for an 8/6 Switched Reluctance Machine: Theoretical concept, design and experimental results", Electric Power Systems Research, vol. 129, pp. 62-74, Dec. 2015.

[7] O. Ellabban, H. Abu-Rub, "Switched reluctance motor converter topologies: A review," IEEE International Conference on Industrial Technology, pp. 840-846, March 2014.

[8] J. Ahn, J. Liang, D. Lee, "Classification and Analysis of Switched Reluctance Converters," Journal of Electrical Engineering and Technology, vol. 5, no. 4, pp. 571-579, November 2010.

[9] Weng Thong, C. Pollock, "Two phase switched reluctance drive with voltage doubler and low dc link capacitance," Industry Applications Conference, vol. 3, pp. 2155-2159, October 2005.

[10] A. K. Mishra, B. Singh, "Control of SRM drive for photovoltaic powered water pumping system", IET Electric Power Applications, vol. 11, Issue 6, pp. 1055-1066, July 2017.

[11] D. Lee, J. Liang, T. Kim, J. Ahn, "Novel passive boost power converter for SR drive with high demagnetization voltage," International Conference on Electrical Machines and Systems, pp.3353-3357, October 2008.

[12] H. Chang, C. Liaw, "An Integrated Driving/Charging Switched Reluctance Motor Drive Using Three-Phase Power Module," IEEE Trans. Ind. Electron., vol. 58, no. 5, pp. 1763 - 1775, Oct. 2011.

[13] Y. Lin, K. Chou, M. Yeh, C. Wang, S. Yu, C. Yang, Y. Chang, C. Liaw, "Design and control of a switched-reluctance motor-driven cooling fan", IET Electric Power Applications, vol. 5, Issue 9, pp. 1813-1826, November 2012.

[14] A. Cordeiro, V. F. Pires, A. J. Pires, J. F. Martins, H. Chen, "FaultTolerant Voltage-Source-Inverters for Switched Reluctance Motor Drives", 13th International Conference on Compatibility, Power Electronics and Power Engineering, pp 1-6, April, 2019.

[15] Q. Sun, J. Wu, C. Gan, J. Guo, "Modular Full-Bridge Converter for Three-Phase Switched Reluctance Motors with Integrated Fault-Tolerance Capability", IEEE Trans. Power Electronics, vol. 34, Issue: 3, pp. 26222634, Mar. 2019.

[16] Y. Hu, C. Gan, W. Cao, W. Li, S. Finney, "Central-Tapped Node Linked Modular Fault-Tolerance Topology for SRM Applications," IEEE Trans. Power. Elect., vol. 31, no. 2, pp. 1541-1554, February 2016.

[17] F. Yi, W. Cai, “A Quasi-Z-source Integrated Multi-port Power Converter with Reduced Capacitance for Switched Reluctance Motor Drives," IEEE Applied Power Electronics Conference and Exposition, pp. 1057-1064, Mrach 2016.

[18] M. Mohamadi, A. Rashidi, S. Saghaian-nezhad, M. Ebrahimi, "A Modified quasi Z-Source Converter for Switched Reluctance Motor Drive", 8th Power Electronics, Drive Systems \& Technologies Conference, pp. 49-54, February 2017.
[19] S. Watkins, J. Corda, L. Zhang, "Multilevel asymmetric power converters for switched reluctance machines", IEEE International Conference on Power Electronics, pp. 195-200, June 2002.

[20] F. Peng, J. Ye, A. Emadi, "An Asymmetric Three-Level Neutral Point Diode Clamped Converter for Switched Reluctance Motor Drives", IEEE Transactions on Power Electronics, vol. 32, $\mathrm{n}^{\mathrm{o}}$ 11, pp. 8618-8631, November 2017.

[21] V. F. Pires, A. Cordeiro, D. Foito, A. J. Pires, J. Martins, Hao Chen , “A Multilevel Fault-Tolerant Power Converter for a Switched Reluctance Machine Drive", IEEE Access, vol. 8, pp. 21917-21931, January 2020.

[22] D. Patil, S. Wang and L. Gu, "Multilevel Converter Topologies for HighPower High-Speed Switched Reluctance Motor: Performance Comparison", IEEE Applied Power Electronics Conference and Exposition, pp. 2889-2896, March 2016

[23] C. Gan, Q. Sun, J. Wu, W. Kong, C. Shi, Y. Hu, " MMC-Based SRM Drives with Decentralized Battery Energy Storage System for Hybrid Electric Vehicles", IEEE Transactions on Power Electronics, vol.34, no.3, pp. 2608 - 2621, March 2019

[24] V. F. Pires, A. Cordeiro, A. J. Pires, J. F. Martins, H. Chen, "A Multilevel Topology Based on the T-Type Converter for SRM Drives", 16th Biennial Baltic Electronics Conference, pp 1-4, October 2018.

[25] D. Lee, H. Wang, J. Ahn, “An Advanced Multi-Level Converter for FourPhase SRM Drive", IEEE Power Electronics Specialists Conference, pp. 2050-2056, June 2008.

[26] V. F. Pires, D. Foito, A. J. Pires, A. Cordeiro, J. F. Martins, H. Chen, "Multilevel Converter Fed SRM Drive for Single Stage PV Array Based Water Pumping", 45th Annual Conference of the IEEE Industrial Electronics Society, pp. 6361-6366, October 2019.

[27] V. F. Pires, A. J. Pires, J. F. Martins, C. Hao, "A quasi-Z-source Converter to Feed a Switched Reluctance Drive with Multilevel Voltages", 44th Annual Conference of the IEEE Industrial Electronics Society, pp. 3706-3711, October 2018. 